Festschrift für Hans-Joachim Priester 


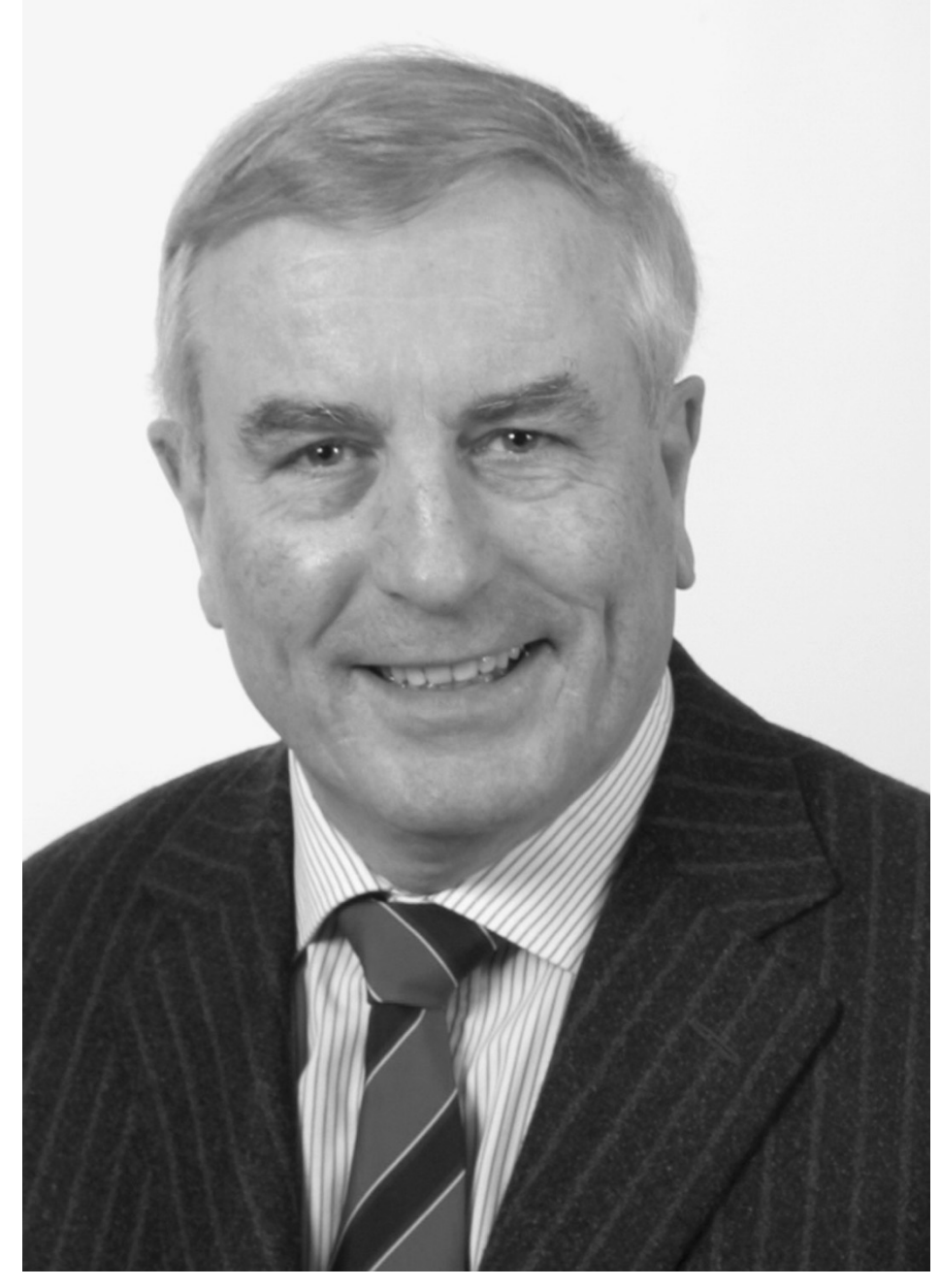

Hans. Joachim livieskr 


\section{FESTSCHRIFT FÜR}

HANS-JOACHIM

PRIESTER

ZUM 70.GEBURTSTAG

herausgegeben von

Peter Hommelhoff

Peter Rawert

Karsten Schmidt

2007

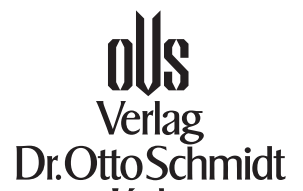

Köln 
Bibliografische Information

der Deutschen Nationalbibliothek

Die Deutsche Nationalbibliothek verzeichnet diese Publikation in der Deutschen Nationalbibliografie; detaillierte bibliografische Daten sind im Internet über http://dnb.d-nb.de abrufbar.

Verlag Dr. Otto Schmidt KG

Gustav-Heinemann-Ufer 58, 50968 Köln

Tel. 02 21/937 38-01, Fax 02 21/937 38-943

info@otto-schmidt.de

www.otto-schmidt.de

ISBN 978-3-504-06036-7

C2007 by Verlag Dr. Otto Schmidt KG, Köln

Das Werk einschließlich aller seiner Teile ist urheberrechtlich geschützt. Jede Verwertung, die nicht ausdrücklich vom Urheberrechtsgesetz zugelassen ist, bedarf der vorherigen Zustimmung des Verlages. Das gilt insbesondere für Vervielfältigungen, Bearbeitungen, Übersetzungen, Mikroverfilmungen und die Einspeicherung und Verarbeitung in elektronischen Systemen.

Das verwendete Papier ist aus chlorfrei gebleichten Rohstoffen hergestellt, holz- und säurefrei, alterungsbeständig und umweltfreundlich.

Einbandgestaltung: Jan P. Lichtenford, Mettmann

Textformatierung: A. Quednau, Haan Druck und Verarbeitung: Bercker, Kevelaer Printed in Germany 